\title{
The Study of Foreign Exhibitions in China (Zhejiang) Pilot Free Trade Zone-Mainly with Marine Characteristics
}

\author{
HU Huimin*, HE Fangjie \\ School of Foreign Languages, Zhejiang Ocean University, Zhoushan316000, China
}

*Corresponding Author: HU Huimin, School of Foreign Languages, Zhejiang Ocean University, Zhoushan316000, China

\begin{abstract}
Foreign exhibitions have become an important platform to promote cooperation and dialogue between China and other countries and regions. Exhibition economy plays an increasingly obvious role in promoting national economy, and international exhibition industry has great development potential. Based on the analysis of the deficiency of Zhoushan's foreign exhibition development and the necessity and feasibility of Zhoushan's foreign exhibition development, this paper puts forward the idea of developing foreign exhibition with Zhoushan's marine characteristics to promote the development of Zhoushan city.
\end{abstract}

Keywords: Foreign exhibition, Zhoushan, Marine characteristics

\section{The Status of Foreign Exhibitions in China}

Foreign exhibition, refers to the subject, object, and contents of the exhibition with foreign element in the exhibition. Foreign exhibition is mainly a kind of special exhibition related to foreign-related enterprises, which generally includes two forms: local enterprises going abroad to participate in the exhibition and developing international exhibition locally to attract foreign enterprises to participate in the exhibition. In recent years, with the increasing status of China in international economy and trade, large-scale exhibitions on foreign affairs held in line with China's diplomatic strategy have become an important platform for China to deepen cooperation and dialogue with key countries and regions in the world. Therefore, the foreign exhibition industry currently has a lot of potential space to be explored. According to the incomplete statistics, since the 1990s, China's exhibition industry has been growing at a rate of about $20 \%$ a year. At present, it has initially formed an international convention and exhibition center city with Shanghai, Beijing, Guangzhou and other major cities as the core. The foreign exhibitions are deeply connected to international organizations and play a role as a platform. The high-level forums, economic and trade negotiations, trade exhibitions and humanities activities are the core contents of the exhibition, and an open cooperation platform is constructed. The exchanges in the humanities field continued to deepen, and all parties used the exhibition as a carrier to carry out multi-field cooperation. Through hard development, a number of professional exhibitions have appeared in China, and gradually formed a world-renowned exhibition, such as The China Import and Export Fair and The China Beijing International Fair for Trade in Services.

On June 8, the first China-Central and Eastern Europe National Expo and International Consumer Goods Fair and the 21st China Zhejiang Investment and Trade Fair officially began. Approved by the Party Central Committee and the State Council, this year, the Central and Eastern Europe Expo was officially upgraded to a national-level exhibition, renamed China-Central and Eastern Europe National Expo and International Consumer Goods Expo, becoming the first large-scale institutional foreign exhibition in Zhejiang. The theme of this year's Expo will be "deepening open cooperation, mutual benefit and win-win". This has brought certain influence and reference to the development of Zhejiang's exhibitions. At Zhoushan, there are also some small Foreign exhibitions such as Zhoushan International Sand Sculpture Festival, Zhoushan International Boat Show and Tea Culture Exhibition, and International Islands Tourism Conference. The exhibitions currently held in Zhoushan are small in scale and not too wide in foreign countries. Compared with the large-scale Foreign exhibitions such as the Canton Fair and the Shanghai World Expo, the gap is very large, and it has not brought about a large social impact and international influence. 


\section{THE SHORTAGE OF FOREIGN EXHIBITIONS IN ZHOUSHAN}

- The exhibition quality is not high. One is the lack of influential brand exhibition. A successful professional exhibition has the following characteristics: gather the most representative enterprises and their most representative products in an industry or field, and organize a large number of professional buyers. In recent years, Zhoushan has made great progress in the development of exhibition economy. However, due to the short holding time of the exhibition and the insufficient publicity, the brand effect with international influence has not been formed. Second, the scale of exhibition activities is not large. As an economy of scale, exhibition can only be competitive when it reaches a certain scale. According to the experience of the domestic exhibition industry, only when the exhibition area is more than 30,000 square meters can it be profitable. Due to the small economic aggregation and limited market capacity of Zhoushan, some industrial exhibitions are at a disadvantage in the competition with other cities. For example, the international yacht show in Zhoushan is tepid compared with the grand scenes in Xiamen, Zhuhai and other places.

- Lack of professional exhibition companies and talents. Exhibition industry is a highly professional industry, involving planning, marketing, management and other fields, exhibition planning directly affects the effect of activities. Zhoushan convention and exhibition industry started relatively late. Due to the lack of professional talents and professional exhibition companies, the organization of exhibitions generally relies on government departments to approve tasks, the performance incentive mechanism is not perfect, living by financial subsidies, the market awareness and motivation is not strong, the publicity is not enough, the influence is not strong. The management system of Zhoushan exhibition activities also needs to be improved.

- Professional supporting facilities and services need to be further improved. At present, there is no special exhibition center in Zhoushan city. With the increase of the number and scale of exhibitions, the standards of storey height and fire protection of temporary venues do not meet the requirements of professional exhibitions, and professional exhibition venues are needed. In addition, exhibition needs relevant supporting services such as booth construction, exhibition equipment rental and Internet publicity, and Zhoushan lacks relevant supporting industries.

\section{THE NECESSITY AND FEASIBILITY ANALYSIS OF DEVELOPING FOREIGN EXHIBITION IN ZHOUSHAN}

\subsection{Necessity}

Exhibition industry is conducive to promoting the scientific positioning of urban functions; The development of exhibition industry will promote the construction of urban infrastructure and make the city function more perfect. The optimization of the city function of the exhibition industry is reflected in the improvement of the city's living function, the strengthening of the city's market function and the enrichment of the city's communication function. Foreign exhibitions can not only promote the circulation of goods at home and abroad, but also drive the contacts and exchanges between countries in trade, investment, culture and various fields, and promote international economic relations from various aspects such as logistics, capital and interpersonal communication.

With the gradual deepening of economic globalization, domestic trade can no longer meet the economic development needs of various countries. Generally, enterprises with certain strength will choose foreign trade and transnational investment to promote the growth and development of enterprises. Foreign exhibition is a platform that can directly gather excellent domestic and foreign enterprises and many advanced products in a short time. The main goal of Foreign exhibition is to help enterprises to win orders and further communication and then achieve cooperation, which helps enterprises to expand overseas trade and drives the development of enterprise trade. Foreign exhibition provides information exchange platform for exhibitors and customers. However, in international trade, it takes time for buyers and sellers to get to know each other and reach a deal. Therefore, after the exhibition, further communication and information interaction can be maintained so as to form a further trade relationship. Foreign exhibition enables enterprises to expand their international popularity, increase their business contact, and realize some potential supply capabilities. It provides opportunities for the follow-up negotiations and exchanges between enterprises, and is an 
effective way for enterprises to improve brand awareness and expand the international market. Second, the foreign exhibition also produce some indirect economic effect related to the exhibition industries and related to the participating industries. According to the International Exhibition Alliance (UFI), only $20 \%$ of the economic benefits created by the exhibition are within the exhibition industry. $80 \%$ are owned by related industries such as commerce, hotel, food, transportation, telecommunications, advertising and other related industries. Foreign exhibitions play an obvious role in driving the economy of cities and enterprises.

Foreign exhibition needs enterprises to travel across the country, and a large number of population flow is bound to drive the tourism boom of the exhibition venue. During the exhibition period, if the city where the exhibition is held leaves a deep impression on the exhibitors and enjoys a high degree of satisfaction, it will have a subsequent impact on the local tourism development and urban construction, attract the development of other exhibitions and further drive the development of local tourism. For example, the brand effect of China-South Asia Expo promotes the overall image of Kunming, and the rapid convergence of people flow, logistics, capital flow and information flow makes the city's popularity expand rapidly. "Kunming model" was once regarded as a typical case and successful model of exhibition industry for reference and learning by all regions. A large number of cities scramble to put forward the goal of accelerating the building of "exhibition capital". As an accelerator and booster of economic development, exhibition economy has increasingly become an important point to enhance urban competitiveness. Therefore, the exhibition industry is known as the "city card", which can improve the international and domestic popularity of the city where the exhibition is held, and indirectly bring economic effects to the urban development. Zhoushan can make use of its unique geographical and policy advantages to carry out foreign exhibitions, so as to promote the development of the city and improve its popularity. At the same time, promote the development of China (Zhejiang) Pilot Free Trade Zone.

\subsection{Feasibility}

\subsubsection{Regional Advantages}

Zhoushan is located at the intersection of the golden coastline in eastern China and the golden waterway of the Yangtze river, and is backed to the vast economic hinterland of the Yangtze river delta. It is a maritime gateway and channel open to the outside world in the Yangtze river basin and the Yangtze river delta. Zhoushan and the emerging port cities in Asia Pacific are radiating in a fan shape. The cross-sea bridge integrates zhoushan into Shanghai's 3-hour economic circle, and Zhoushan plans to realize "one-hour traffic circle" from Zhoushan to Hangzhou. Zhoushan is speeding up the early stage of the Yongzhou railway project, which is expected to be completed and open to the public by 2025. Signed by the Premier of the State Council, the State Council's "Agree on the Approval of Zhejiang Zhoushan Putuoshan Airport Opening to the Outside World" agreed that Putuoshan Airport will be opened to the outside world and become the first international airport in Zhoushan. The Zhoushan Archipelago New Area has taken a new step in opening to the outside world. This approval can complement the short-board of the Free Trade Zone and is also the practical need of zhoushan to undertake the strategy of national major projects.

\subsubsection{Policy Advantages}

Zhoushan is located in the Yangtze river delta exhibition economic belt -- an exhibition industrial belt centering on Shanghai and relying on Nanjing, Hangzhou, Ningbo, Suzhou and other cities. The Yangtze river delta city exhibition union will promote the interaction and win-win situation among various cities through the construction of information exchange platform, statistical analysis platform, talent training platform and brand training platform, so as to achieve the goal of harmonious development. The industrial belt has a high starting point, strong government support, reasonable planning and layout, and strong trade color. It is greatly influenced by the location structure and has great development potential.

China (Zhejiang) Pilot Free Trade Zone is the core area connecting "One Belt And One Road" and Yangtze River Economic Belt.The strategic positioning of China (Zhejiang) Pilot Free Trade Zone is: taking institutional innovation as the core and copying and promoting as the basic requirements, the Zhejiang Pilot Free Trade Zone will be built into an important demonstration zone of maritime 
opening in the eastern region, a pilot zone of international commodity trade liberalization and a resource allocation base with international influence. Zhoushan is another state-level new area in China, following Shanghai Pudong New Area, Tianjin Binhai New Area and Chongqing Liangjiang New Area. In recent years, Zhoushan's economy has continued to develop rapidly and steadily, and its economic growth rate is in the forefront of the province, In particular, multiple national strategies such as "Yangtze River Economic Belt", "Zhoushan Archipelago New Area", "Zhoushan Jianghai Combined Transport Service Center" and "Pilot Free Trade Zone" have been implemented one after another, with obvious marine economic characteristics. The municipal government proposes to cultivate a multi-billion marine industry cluster during the 13th Five-year Plan period. The characteristics of Zhoushan's marine economy are further highlighted. The added value of Marine economy accounts for $72 \%$ of the gross domestic product. The mature industrial foundation of zhoushan's marine economy lays a solid industrial economic foundation for the development of exhibition industry.

\subsubsection{Unique Marine culture}

Rich tourism resources and profound island cultural heritage are important resources for Zhoushan exhibition activities. Zhoushan has beautiful natural scenery and pleasant climate. The mountains and seas have unique landscapes and numerous historical sites. They have unique marine culture and island customs culture, which constitute an attractive natural and cultural environment for the exhibition. In addition, as an important tourist city in China, Zhoushan has more than a thousand landscapes such as Buddhism culture, Shanhai culture, Fishing customs culture and Jinyong martial arts culture. Through the inheritance, expansion and derivation of traditional Marine culture, Zhoushan has unique marine culture charm.

Zhoushan can make use of its unique geographical and policy advantages to carry out foreign exhibitions in China (Zhejiang) Pilot Free Trade Zone, so as to promote the development of the city and improve its visibility.

\section{The SUgGeSTIONS OF DEVELOPING FOREIGN EXHIBITIONS In CHINA (ZHEJIANG) PILOT FReE Trade ZONE}

\subsection{Government Support}

According to the experience of the development of exhibition industry, the development of the exhibition industry to a certain stage requires the government to use legal and economic means to intervene and manage to promote its healthy development. In the long run, marketization and commercialization of exhibitions are inevitable trends, therefore Zhoushan to expand exhibition market and stronger exhibition brand, the government should play its role in exhibition development and formulate the strategic plan for the development of exhibition industry. The government should thoroughly study and determine the industries that need to be stimulated by exhibition, formulate the strategic plan for the development of exhibition industry in Zhoushan city, and put forward directional guidelines for the development of exhibition according to the urban development plan.

The government can introduce top-level system design and standardize exhibition development. It is suggested that Zhoushan should strengthen top-level design according to the actual development of local exhibition, including promulgation of relevant plans, local laws and regulations, improvement of market access mechanism, formulation of the list of rights and responsibilities of exhibition industry, and support the establishment of industry associations and modern exhibition enterprises.

It can implement relevant preferential policies to support the exhibition brand to become bigger and stronger. Clarify relevant fiscal and tax incentives, and improve incentive mechanisms, such as reducing or exempting taxes for exhibition organizers and exhibitors. Formulate industrial support policies conducive to the development of the convention and exhibition industry, promote the smooth development of the exhibition industry, and focus on fostering land acquisition, fund raising, infrastructure construction, personnel training, and external exchanges.

It can use government power to reach out and build relationships. First, relevant exhibition institutions or offices should be set up in government departments, and then the government should promote and establish relations with other countries: the conferences and exhibitions that serve the mainstream 
industries of Zhoushan city should be promoted at home and abroad, and when conditions allow, help exhibition enterprises to establish strategic alliance relations with relevant industries at home and abroad. Invite buyer to Zhoushan to make on-the-spot investigation in a planned way, make buyer hold exhibition activity to Zhoushan to have a perceptual understanding, arouse their interest. This approach has small investment, but quick effect and offers more companies the opportunity to meet international buyers.

It can further improve urban infrastructure and accelerate development of exhibition venues and supporting facilities. The construction of modern exhibition venues and supporting facilities is to meet the actual needs of international and high-standard exhibition activities. In the construction process of exhibition venues, in addition to reasonable layout, three aspects should be combined. First, the development of exhibition venues should be combined with the economic scale of Zhoushan. The development of exhibition venues is based on the certain economic foundation and economic stock of the host city, and too many or too few exhibition venues are not conducive to the development of exhibition industry. Second, with the combination of market demand, exhibition venue construction should be market-oriented, not blindly pursue the big and complete. It is not just simply regarded as a landmark building of a city. Third, combined with Zhoushan master plan, when compiling or revising the master plan of the city, full consideration should be given to the needs of exhibition development.

\subsection{Make use of the Policy Advantages of the Free Trade Zone}

The approval of the free trade zone in Zhoushan has brought unprecedented new opportunities for the development of the exhibition industry. The Management Committee of Zhejiang Pilot Free Trade Zone issued 96 pieces of experience in replicating the reform pilots of the two batches of free trade pilot zones. As early as the Shanghai Free Trade Zone was approved, the plan proposed to expand the service industry, one of which the item is professional service (the exhibition industry belongs to this category). The free trade zone's policies on trade facilitation, government function transformation, rule of law environment optimization, financial mechanism innovation, tax preference and entry and exit of high-end talents are great benefits to the development of the exhibition industry. The free trade zone's policies support the development of cultural foreign trade. We can explore a new mode of bonded supervision of cultural products, and promote the development of cultural businesses such as culture and art, digital publishing, animation and games, and art trading. Relying on the special customs supervision area, Zhoushan can develop the import and export industry with cultural characteristics.

\subsection{Accelerate the Training of Professional Exhibition Talents}

"Exhibition is the most fashionable and fresh thing, so innovation is the soul of exhibition. To attract visitors from various countries to participate in the exhibition, it is necessary to have selling points. The selling point comes from creative people." Guo mu, chairman of Yuanda international exhibition co., LTD., expresses the core quality of exhibition talents. Accelerate talent training and build an excellent exhibition team. Actively carry out the storage and training of exhibition talents, including the total number of exhibition practitioners, regional talent structure, talent leveland human resources training structure. The government should send professionals abroad for training and observation or invite foreign industry personnel to give lectures and training guidance, guide them to have the right concept, in order to improve the professional level of exhibition professionals, and actively cultivate local professionals. In the China (Zhejiang) Pilot Free Trade Zone, high-end talents and talented talents employed in the headquarters of the Zhejiang Pilot Free Trade Zone were supported by the documentary policy of "Opinions on implementing new policies on talent development to create new heights for talents in marine economy".

\subsection{Define Marine Characteristics and Create Several Brand Foreign Exhibitions}

The Yangtze River Delta Economic Belt is the frontier of China's exhibition economy development. Zhoushan is surrounded by some first- and second-tier cities such as Shanghai, Hangzhou, Ningbo, as well as a number of economically developed county-level cities such as Yiwu and Cixi. These cities have developed exhibition economy. Zhoushan Exhibition Industry wants to survival in the environment of group males must be positioned, adhere to characteristics, and develop in dislocation. Take the road of industrialization and branding, and draw on the advanced experience of successful 
countries and enterprises. Ocean is the biggest resource of Zhoushan, marine economy is the biggest bright spot of Zhoushan. The development of marine economy is the economic development priority of Zhejiang province in recent years, the provincial party committee and provincial government have high requirements for the future development of Zhoushan, and think that Zhoushan should be put in the international background to consider the development. Therefore, we must seize the opportunity, make rational use of Zhoushan's rich marine resources, and develop distinctive marine exhibitions.

\subsubsection{Marine Economy Exhibition}

Zhoushan was once an important hub of the maritime silk road. Nowa new pattern of Marine emerging industries have been constructed here. From marine biotechnology to high-end marine equipment; From China's first state-level new area with the theme of marine economy to Zhoushan Jianghai Intermodal Service Center, standing at the forefront of the innovative development of marine economy, Zhoushan has walked out of a deep blue sea track.

According to preliminary calculations, the added value of marine economy in Zhoushan reached 82.4 billion yuan in 2017, a year-on-year increase of 9.0\%. The development pattern of marine emerging industries focusing on marine high-end equipment manufacturing and marine life has taken shape. Zhoushan can actively absorb the successful experience of China Ocean Economic Expo, and then actively cater to the "One Belt and One Road", "Yangtze River Economic Belt", "Free Trade Zone Strategy" and other national strategic requirements in terms of theme design, venue layout, and investment promotion. Actively bring into play the function of exhibition window and platform, to develop the Marine economy exhibition.

\subsubsection{Marine Tourism Exhibition}

Zhoushan is rich in marine tourism resources and has a profound cultural heritage. This is a unique and irreplaceable resource. Zhoushan City has always been famous at home and abroad with Putuoshan, Shenjiamen night stalls, Zhujiajian, Taohua Islandand other tourist areas. In 2017, Zhoushan has reached 55 million tourists. In order to enhance the interaction between the tourism industry and the exhibition industry, the government can offer free public transport and ticket discounts for scenic spots to purchasers and exhibitors. The next step is to rely on existing resources, dig deep into the cultural connotation, find the right market, create a number of International Islands Tourism Conference, East Sea Festival and other exhibition brands. At present, there is still a lot of room for improvement in marine leisure sports in China. Therefore, it is suggested to introduce international advanced marine leisure products bonded exhibition in the Free Trade Zone to attract tourists' experience, extend their stay, increase the added value of tourism and improve the attraction of the exhibition.

\subsubsection{Marine Culture Exhibition}

Zhoushan has a long history of marine culture, with rich marine resources and unique features.

Ma 'ao in Zhoushan is one of the first places where man went to the sea. As early as five or six thousand years ago, Ma 'ao created the "Island Hemudu Culture" and was known as the "No.1 village of the east China sea".

Zhoushan is an important passage of the "Maritime Silk Road". It was used as the starting point or transit station for Xu fu's eastward crossing, Jianzhen's eastward crossing, envoy's visits to the Tang dynasty and Zheng he's voyages to the western seas.

Zhoushan fishery is one of the four famous fishing grounds in the world, and Shenjiamen fishing port is one of the three famous fishing ports in the world. In the fishery production, Zhoushan formed primitive and rough customs of production, life, etiquette and entertainment, and produced Marine art with Zhoushan characteristics represented by "Zhoushan gong and drum" and "Zhoushan fisherman's chant". Fishermen's kaiyang festival and xieyang festival have been included in the national intangible cultural heritage protection list.

Zhoushan marine folk art is colorful, Fishermen Painting, Zhoushan Lacquer Painting, Zhoushan Shell Carving, Ocean Paper Cutting, Zhoushan Boat Boxing and so on all show the unique charm of Zhoushan marine culture. 
Driven by both the market and the government, numerous cultural industries have been developing rapidly and new forms of business have been formed, forming the marine cultural industry with Zhoushan characteristics, which means that the marine cultural industry is gradually becoming a new economic growth point in Zhoushan and promoting the new economic development of Zhoushan. Zhoushan can carry out foreign exhibitions such as marine culture derivatives and marine customs experience, so as to further promote Zhoushan marine culture at home and abroad and promote exchanges and cooperation among cultural enterprises of various countries.

\section{The LONG-TERM DEVELOPMENT OF FOREIGN EXHibitions In China (ZHEJIANG) PILOT FreE TRADE ZONE}

With the help of the "Internet + exhibition" model we can accelerate the development of new internetbased exhibition formats, and promote the application of APP, We Chat and other Internet tools in the exhibition industry. We can also use the "Internet + " to expand the coverage, so that more people can see and understand the exhibition, and enhance the influence of foreign exhibitions at home and abroad.

New exhibition modes, such as overseas exhibition tour and joint exhibition, can not only enhance the reputation of the exhibition brand, but also make the never-ending exhibition gradually become a reality.

The development of exhibition industry depends on the speed of a country's economic development and the breadth and depth of opening to the outside world. China's foreign trade has achieved rapid development since China joined the WTO, and the development speed of exhibition industry in recent years is complementary to each other. We should be based on the steady development of the economy, stand firm, look to the world, seek development in the competition, use laws and policiescorrectly, and make achievements in the world exhibition industry!

\section{REFERENCES}

[1] Aviv Shoham. Performance in Trade Shows and Exhibitions[J]. Journal ofGlobal Marketing,1999,12(3).

[2] Timothy M. Smith,Kazuyo Hama,Paul M. Smith. The effect of successful trade show attendance on future show interest: exploring Japanese attendee perspectives of domestic and offshore international events[J]. Journal of Business \& Industrial Marketing,2003,18(4/5).

[3] 蔡婕萍,许和连.上海市涉外会展对外向型经济发展影响分析J].华东经济管理,2013,27(08):1-5.

[4] 森英, 刘冰. 会展法规与实务[M]. 2010.

[5] 刘辉,王耀燕. 我国展会的发展现状及其发展对策浅析 J]. 湖北经济学院学报(人文社会科学版),2005(0 2): 63-64.

[6] 李智,马丽卿.产业融合背景下的舟山海洋文化产业新发展[J].海洋开发与管理,2018,35(01):28-32.

[7] 毛润泽.会展业的发展与城市的能性、能级及能位[J].城市问题,2010(04):7-10.

[8] 俞萍.海洋文化元素在舟山旅游商品开发设计中的应用[J].包装工程,2019(08):305-310.

[9] 舟山数字文化网. http://www.zsszwh.cn.

Citation: HU Huimin, HE Fangjie. "The Study of Foreign Exhibitions in China (Zhejiang) Pilot Free Trade Zone-Mainly with Marine Characteristics". International Journal of Humanities Social Sciences and Education (IJHSSE), vol. 6, no.9, 2019, pp. 101-107. doi: http://dx. doi.org/10.20431/2349-0381.0609011.

Copyright: (C) 2019 Authors. This is an open-access article distributed under the terms of the Creative Commons Attribution License, which permits unrestricted use, distribution, and reproduction in any medium, provided the original author and source are credited. 